\title{
Improving Sintering Performance of Specularite Concentrates by Pre-briquetting Process
}

\author{
Jian PAN, Benjing SHI, ${ }^{*}$ Deqing ZHU and Yaping MO \\ School of Minerals Processing and Bioengineering, Central South University, Lushan South Road 932, Yuelu District, \\ Changsha, 410083 P.R. China.
}

(Received on October 13, 2015; accepted on January 20, 2016; J-STAGE Advance published date: March 31, 2016)

\begin{abstract}
With advantages of high Fe grade, less harmful impurities and relatively low price, specularite is one of ideal raw materials for improving sinter grade and reducing raw material cost. However its physicochemical characteristics lead to poor granulating performance and low degree of assimilation and melt generation at high temperature, consequently affect the productivity and quality of sinter. Unfortunately the existing methods of improving sintering performance for concentrates are not applicable to specularite concentrates. In this paper, a pre-briquetting process was developed to improve the sintering performance of specularite concentrates. Experimental results of ore blends containing $24 \%-36 \%$ specularite concentrate showed that pre-briqutting process made specularite into larger particles alone instead of distributing in sintering layer, consequently improved the green bed permeability by $10.28 \%-25.91 \%$, the vertical sintering speed and the sintering productivity by $5.40 \%-18.63 \%$ and $7.09 \%-25.81 \%$, respectively. Furthermore, the sinter of pre-briquetting process obtained a better tumble strength which was achieved at a lower fuel rate. By pre-briquetting process, the sinter tumble strength is improved by $1.52 \%$ while the fuel consumption is decreased by $2.00 \mathrm{~kg} / \mathrm{t}$ under condition that $36 \%$ specularite was contained. Meanwhile, the reducibility $(\mathrm{RI})$ and low temperature reduction disintegration $\left(R D I_{+3.15}\right)$ of sinter could be improved by pre-briquetting process especially when the ratio of specularite was more than $30 \%$. Microscopic observation showed that more calcium ferrite phase and less magnetite appeared in the sinter of pre-briquetting than that of traditional sintering process, means the mineral composition and structure got ameliorated by pre-briquetting process.
\end{abstract}

KEY WORDS: specularite concentrate; pre-briquetting; sintering; permeability.

\section{Introduction}

As the fundamental industry of national economy, iron and steel industry's development leads rapid increase in demand for iron ore in China. As the largest iron oreproducing country which accounts for about $45 \%$ of the world's iron ore production, China still imported about 850 Mt iron ore, account for $65 \%$ of the world's seaborne iron ore trade in 2013. ${ }^{1)}$ Faced with situation that the amount of iron ore that has high ferrous grade and few harmful impurities decreased while the price increased in the international markets, the steel mills have more and more pressure for materials and production cost. ${ }^{2,3)}$ Therefore, research and rational utilization of imported iron ore would be a longterm strategy for Chinese steel industry in energy-saving and cost-reducing.

With features of high ferrous grade, few harmful impurities and relatively low price, specularite has been gradually accepted by steel mills in the recent years. ${ }^{4-6)}$ According to the analysis of world iron ore reserves, specularite is distributed widely in the world and abundant in some countries

\footnotetext{
* Corresponding author: E-mail: shi_benjing@126.com. DOI: http://dx.doi.org/10.2355/isijinternational.ISIJINT-2015-578
}

such as Canada and Brazil. But due to its own characteristics that hard texture, undesirable particle size and shape, dense and smooth particle surface and poor assimilation performance, it is hard to be used in large amount for the production of sinter and pellet especially the former, so it have not yet been widely applied in production. ${ }^{7-11)}$ Many steel mills like Baosteel, Wisco, Hansteel and Valin Group found that, adding large amount of specularite in sinter mixture would deteriorate mixture's granulating and green sinter bed's permeability, worsen productivity and tumble index of sinter and increase solid fuel consumption. As a result, the blend ratios of specularite in sintering plant are normally 3\%-10\% except about $20 \%$ in individual steel mill.

On account of huge potential for utilization, researchers have conducted some studies on sintering or pelletizing with high ratio of specularite. These researches mainly focus on modification of surface properties through fine milling or HPRG (high pressure roll grinding), strengthening granulating process by ameliorating agglomeration process like CAP (composite agglomeration process) or adding binder, and selective ore proportioning for sintering..$^{8,11-18)}$ To cope with the degradation of iron ore, Nippon Steel Corporation developed a innovative pretreatment technology for sintering named as the "SPEx-II" (Semi-Pellet Expansion step-II), 
which keeps the sintering productivity even if the fine iron ores like pellet-feed was used as a sinter feed by making hard semi-pellets with a roll crusher, a drum pelletizer and a dryer. ${ }^{19,20)}$ Due to a tendency of higher generation of pellet feed with the implementation of new projects of itabirite ore treatment, a new technology was developed by VALE to produce cold bonded minipellets using natural pellet feed and incorporate into the sinter feed to improve chemical and physical quality of sinter. ${ }^{21)}$ The results have proved the technical feasibility for production of minipellets, which possess proper physical qualities for handling and transport, using $100 \%$ natural pellet feed (without further grinding) with different alternatives binders and additives.

To some extent, existing measures are effective for sintering with high ratio of specularite. However, some defects can't be ignored at the same time, such as fine grinding means high energy consumption, selective ore proportioning means special material requirements. So a study was conducted on sintering with high ratio of specularite and a pre-agglomeration method, pre-briquetting process, which is different from pelletizing sintering, SPEx-II and CAP, also different from cold bonded minipellets or semi-pellets, was developed to improving sintering performance of specularite concentrates. This paper presents the effect and improvements of pre-briquetting process on sintering performance of specularite concentrates.

\section{Experimental Procedure}

\subsection{Raw Materials}

The specularite (Labeled A) used in this study is one kind of imported ore from Canada, other iron ores (Labeled B-G) are normally used in some steel mills. The chemical composition, size distribution and physical properties of materials are shown in Tables 1, $\mathbf{2}$ and $\mathbf{3}$. The particle morphology of specularite is shown in Fig. 1.

The specularite contains $64.74 \%$ total iron, $5.65 \% \mathrm{SiO}_{2}$ and little other impurities, which reveals it is a kind of good feed for ironmaking. However, what calls for special attention is that the size of specularite is $99.90 \%$ passing 0.5 $\mathrm{mm}$, with $38.55 \%$ between $0.2 \mathrm{~mm}$ and $0.5 \mathrm{~mm}$. Effective granulation is the formation of quasi particle structure with particles $1-3 \mathrm{~mm}$ as nuclei and fine particles below $0.2 \mathrm{~mm}$ as adhering layer, particles between $0.2-1 \mathrm{~mm}$ should be as

Table 1. Chemical composition of raw materials (wt./\%).

\begin{tabular}{cccccccccc}
\hline Item & $\mathrm{Fe}_{\text {total }}$ & $\mathrm{FeO}$ & $\mathrm{SiO}_{2}$ & $\mathrm{CaO}$ & $\mathrm{MgO}$ & $\mathrm{Al}_{2} \mathrm{O}_{3}$ & $\mathrm{P}$ & $\mathrm{S}$ & LOI \\
\hline $\mathrm{A}$ & 64.74 & 0.62 & 5.65 & 0.45 & 0.10 & 0.85 & 0.026 & 0.039 & 0.17 \\
$\mathrm{~B}$ & 62.70 & - & 4.53 & 0.19 & 0.10 & 2.08 & 0.091 & 0.012 & 3.04 \\
$\mathrm{C}$ & 60.11 & - & 3.78 & 0.19 & 0.07 & 2.17 & 0.095 & 0.035 & 6.46 \\
$\mathrm{D}$ & 55.92 & - & 6.52 & 0.13 & 0.10 & 2.54 & 0.071 & 0.030 & 8.94 \\
$\mathrm{E}$ & 64.34 & 0.50 & 5.51 & 0.05 & 0.04 & 0.96 & 0.059 & 0.010 & 1.11 \\
$\mathrm{~F}$ & 48.94 & 6.41 & 11.51 & 2.55 & 0.61 & 4.37 & 0.790 & 0.260 & 6.73 \\
$\mathrm{G}$ & 62.14 & 17.56 & 5.69 & 0.83 & 1.20 & 0.63 & 0.053 & 0.640 & 2.29 \\
Burntlime & 0.15 & - & 2.05 & 69.33 & 0.13 & 0.02 & 0.021 & 0.055 & 27.71 \\
Limestone & 0.61 & - & 3.09 & 51.40 & 2.03 & 0.22 & 0.065 & 0.020 & 41.91 \\
Dolomite & 0.24 & - & 0.84 & 33.21 & 18.93 & 0.34 & 0.014 & 0.042 & 45.05 \\
Anthracite & 0.61 & - & 4.45 & 1.55 & 0.10 & 3.35 & - & 0.040 & 88.96
\end{tabular}

*Proximate analysis of anthracite: $11.04 \%$ of ash, $78.81 \%$ of fixed carbon and $10.15 \%$ of volatile matter.

Table 2. Size distribution of raw materials (wt./\%).

\begin{tabular}{crrrrrrrrr}
\hline Size $/ \mathrm{mm}$ & +8.0 & $5.0-8.0$ & $3.0-5.0$ & $1.0-3.0$ & $0.5-1.0$ & $0.2-0.5$ & $0.063-0.2$ & -0.063 \\
\hline $\mathrm{A}$ & 0.00 & 0.00 & 0.00 & 0.00 & 0.10 & 38.55 & 53.87 & 7.48 \\
$\mathrm{~B}$ & 8.65 & 22.81 & 15.73 & 29.21 & 8.76 & 3.60 & 7.98 & 3.26 \\
$\mathrm{C}$ & 5.07 & 14.72 & 15.86 & 34.84 & 12.58 & 6.39 & 7.00 & 3.55 \\
$\mathrm{D}$ & 25.89 & 12.58 & 10.41 & 19.64 & 11.88 & 7.92 & 7.41 & 4.26 \\
E & 2.57 & 8.96 & 8.87 & 21.33 & 8.53 & 7.09 & 25.90 & 16.75 \\
F & 4.83 & 10.47 & 12.04 & 27.44 & 13.39 & 10.47 & 15.71 & 5.64 \\
G & 3.01 & 2.18 & 2.49 & 7.26 & 5.81 & 5.71 & 52.29 & 21.27 \\
Burntlime & 0.51 & 1.03 & 5.84 & 30.05 & 21.03 & 12.82 & 25.23 & 3.49 \\
Limestone & 0.00 & 1.44 & 9.61 & 38.14 & 18.64 & 9.06 & 11.61 & 11.51 \\
Dolomite & 0.00 & 2.86 & 13.23 & 36.54 & 11.23 & 7.59 & 12.75 & 15.79 \\
Anthracite & 0.00 & 1.59 & 9.32 & 39.85 & 20.30 & 11.47 & 13.61 & 3.86 \\
\hline
\end{tabular}


Table 3. Physical properties of iron materials.

\begin{tabular}{ccccc}
\hline Type & $\begin{array}{c}\text { Molecular } \\
\text { moisture/\% }\end{array}$ & $\begin{array}{c}\text { Capillary } \\
\text { moisture/\% }\end{array}$ & $\begin{array}{c}\text { Ballability } \\
\text { index (K) }\end{array}$ & $\begin{array}{c}\text { Specific surface } \\
\text { area/cm } \mathrm{cm}^{-1}\end{array}$ \\
\hline A & 1.42 & 11.41 & 0.14 & 248 \\
B & 8.53 & 17.25 & 0.98 & 761 \\
C & 9.67 & 17.27 & 1.27 & 707 \\
D & 9.59 & 16.00 & 1.50 & 745 \\
E & 3.61 & 14.18 & 0.34 & 286 \\
F & 9.72 & 21.14 & 0.85 & 942 \\
G & 9.64 & 19.35 & 0.99 & 349 \\
\hline
\end{tabular}
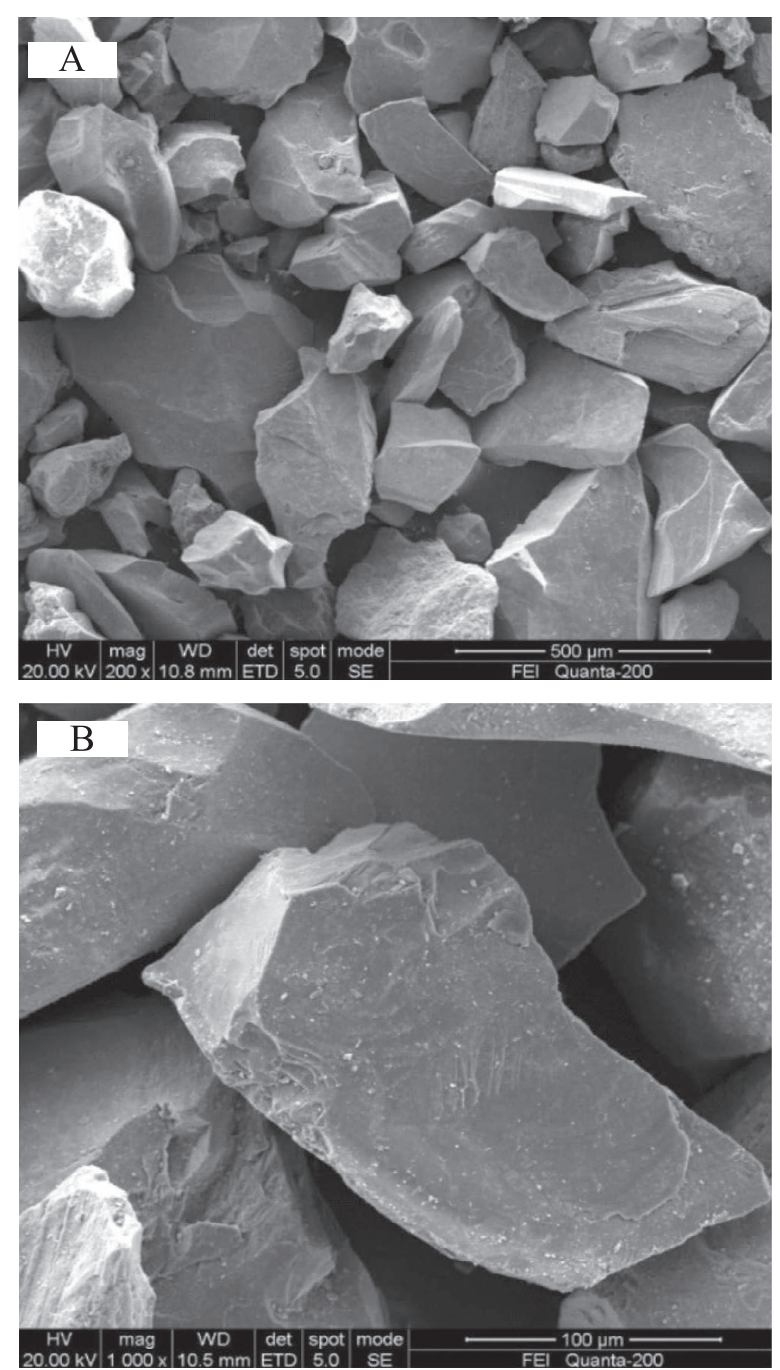

Fig. 1. Particle morphology of specularite under SEM (A: $\times 200$, B: $\times 1000)$.

little as possible because these particles can neither act as the nuclei nor as the adhesion. ${ }^{22)}$ From this perspective, the size composition of specularite is adverse to granulation. Besides unreasonable size composition, it can be seen from Table 3 that the specific surface area and ballability index of specularite are only $248 \mathrm{~cm}^{2} \cdot \mathrm{g}^{-1}$ and 0.14 , respectively. Meantime, the surface of specularite particle is smooth and dense while lacking fine particles or adhesion particles as shown in Fig. 1. All of which mean poor granulating capability of specularite at the same time.
Table 4. Ore blending scheme and target value of sinter.

\begin{tabular}{|c|c|c|c|c|}
\hline Item & Ore type & Base blend & Blend-1 & Blend-2 \\
\hline \multirow{7}{*}{$\begin{array}{l}\text { Iron ore } \\
\text { blends }\end{array}$} & A & $24.0 \%$ & $30.0 \%$ & $36.0 \%$ \\
\hline & B & $20.0 \%$ & $18.4 \%$ & $16.8 \%$ \\
\hline & $\mathrm{C}$ & $25.0 \%$ & $23.0 \%$ & $21.1 \%$ \\
\hline & $\mathrm{D}$ & $13.0 \%$ & $12.0 \%$ & $11.0 \%$ \\
\hline & $\mathrm{E}$ & $5.0 \%$ & $4.6 \%$ & $4.2 \%$ \\
\hline & $\mathrm{F}$ & $5.0 \%$ & $4.6 \%$ & $4.2 \%$ \\
\hline & G & $8.0 \%$ & $7.4 \%$ & $6.7 \%$ \\
\hline \multirow{4}{*}{$\begin{array}{c}\text { Target } \\
\text { value of } \\
\text { sinter }\end{array}$} & $\mathrm{TFe}$ & & $>55.50$ & \\
\hline & $\mathrm{SiO}_{2}$ & & $5.90 \%$ & \\
\hline & $\mathrm{MgO}$ & & $1.70 \%$ & \\
\hline & Basicity $\left(\mathrm{R}=\mathrm{CaO} / \mathrm{SiO}_{2}\right)$ & & 1.80 & \\
\hline
\end{tabular}

\subsection{Experimental Methods}

2.2.1. Compositions of Blends and Target Chemistry Value of Sinter

First of all, the ore blending scheme is documented in Table 4. The difference between Base blend and Blend-1, Blend-2 is the proportion of specularite. The Base blend uses $24 \%$ specularite and the Blend-1 and Blend-2 are proportioned $30 \%$ and $36 \%$ specularite respectively, while other iron fines are decreased by equal proportion. The basicity the $\mathrm{SiO}_{2}$ and $\mathrm{MgO}$ content of sinter are set at 1.80 , $5.90 \%$ and $1.70 \%$, respectively.

\subsubsection{Granulating and Sintering}

The sintering tests were taken through traditional and pre-briquetting processes, both were conducted at pilot scale pot, and covered blending, mixing, granulation, ignition, sintering, cooling, crushing and testing treatment of cooled sinter.

In traditional process, first the proportioned raw materials including iron ores, fluxes, anthracite and sinter return fines $(30 \%)$ were mixed uniformly and then water was added into the mixture. Then the mixture was granulated for 5 min in a $\Phi 600 \mathrm{~mm} \times 1400 \mathrm{~mm}$ drum granulator with 16 $\mathrm{r} / \mathrm{min}$ rotational speed. Different with traditional sintering process, when the pre-briquetting process was taken place, the specularite was pre-briquetted by high pressure briquetting machine before mixing with other sinter feed as Fig. 2(a) shows. The pre-briquetting of specularite is shown in Fig. 2(b). The specularite and additive were blended proportionally, mixed with water and then loaded in the charging box as Fig. 2(c) shown. After the mixture was briquetted by double reversal rollers with several half round grooves of diameter $10 \mathrm{~mm}$ around the circumferential direction of the rollers, the briquettes had been transformed to the shape of cylindrical and then got broken into several sections between 5-50 mm length after dropping on the carrying device, the final product of briquettes which is shown in Fig. 3 was added into the drum granulator with other raw materials. According to the test, under the condition of $8 \%$ bunt lime, $3 \%$ organic binder L (consist of mostly humid acid and a small amount of carboxyl and hydroxyl groups-containing macromolecule organic compound) and moisture of blends 


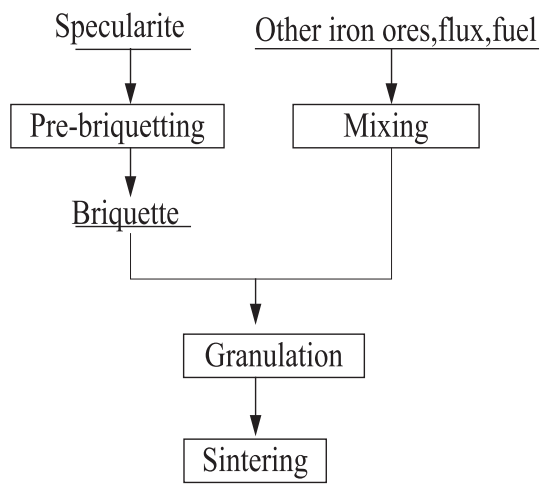

(a)

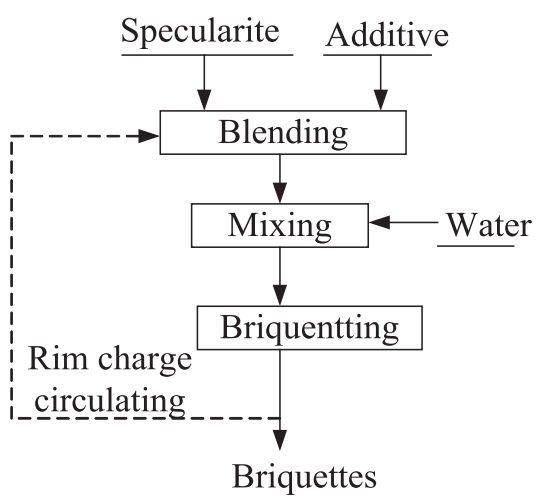

(b)

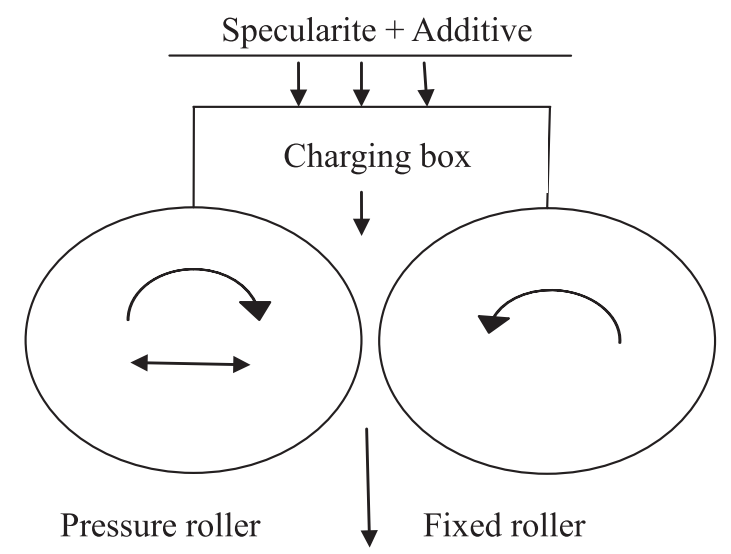

Briquettes

(c)

Fig. 2. Flowsheet of pre-briquetting sintering process (a), Pre-briquetting of specularite (b) and Sketch of pre-briquetting equipment (c).

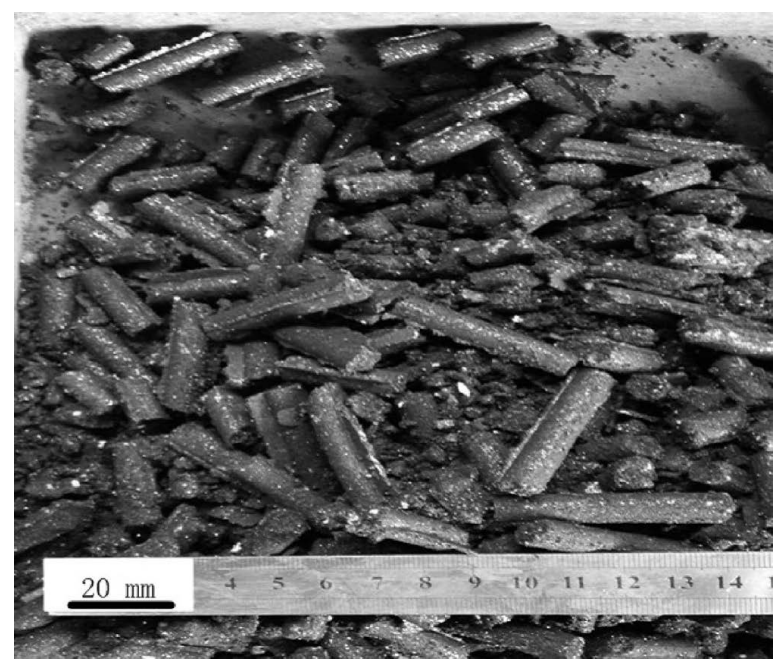

Fig. 3. The final product of briquettes made from specularite concentrates.

at $4.5 \%$, the briquetting parameters of roller pressure at 0.8 $\mathrm{N} / \mathrm{mm}^{2}$, rotary speed at $40 \mathrm{r} / \mathrm{min}$ and rim charge circulating ratio at $20 \%-30 \%$, the yield of pre-briquetting can reach about $70-80 \%$ (mass ratio to charge of the mixture).

After granulation, the granulating efficiency was evaluated by fractions of granules over $3 \mathrm{~mm}$ and sintering mixture permeability of using Voice formula ${ }^{22)}$ which determined from Eq. (1):

$$
\mathrm{KD}=(\mathrm{Q} / \mathrm{S}) \times(\mathrm{h} / \Delta \mathrm{P})^{\mathrm{n}}, \mathrm{J} . \mathrm{P} . \mathrm{U}
$$

Where, $\mathrm{KD}$ is permeability index, $\mathrm{Q}$ is air flow rate $\left(\mathrm{m}^{3} / \mathrm{min}\right), \mathrm{S}$ is bed section area $\left(\mathrm{m}^{2}\right), \mathrm{h}$ means bed height $(\mathrm{mm}), \Delta \mathrm{P}$ means pressure drop $(\mathrm{Pa})$, and $\mathrm{n}$ is constant that usually value at 0.6 .

At the same time, the mixture after granulation was loaded into a $\Phi 180 \mathrm{~mm} \times 700 \mathrm{~mm}$ sinter pot to simulate the industrial sintering. Before loading the granulated mixture into sinter pot, some $1.0 \mathrm{~kg}$ hearth layer consists of sinter between 10-12.5 mm was laid into sinter pot. And then sintering ignition went after loading mixture. The ignition flame temperature was $1100 \pm 50^{\circ} \mathrm{C}$, the ignition time was $1.5 \mathrm{~min}$, the ignition suction was $5000 \mathrm{~Pa}$, the sinter suction was $10000 \mathrm{~Pa}$, and the sinter was cooling for $3 \mathrm{~min}$ at 5000 $\mathrm{Pa}$. After ignition, the exhaust gas temperature was monitored continuously and the sintering time was taken from the time of ignition to the time when the exhaust gas reached to the highest temperature. The finished sinter cake was dropped from a height of $2 \mathrm{~m}$ for three times to simulate the actual condition in a commercial sinter plant. Subsequently, the sinter was screened with $50,40,25,16,10$ and $5 \mathrm{~mm}$ square aperture screen. The sinter above $5 \mathrm{~mm}$ was the product of pot test and that less than $5 \mathrm{~mm}$ was the return fines. Finally the product was tested to determine relative technical indices including vertical sintering speed (V.S.S), productivity, tumble index (TI), solid fuel consumption, and all that were obtained on the premise of return fines 
balanced $(\mathrm{RFB}=1 \pm 0.05)$. In order to compare the effect of pre-briquetting and traditional process on the granulation and sintering performance, the anthracite ratio and moisture in sinter mixture were fixed at $3.79 \%$ and $7.5 \%$ respectively, also the total granulation time in drum was kept for $5 \mathrm{~min}$.

The tests of RI (reduction index) and RDI (reduction degradation index) were operated according to GB/T1324191 and GB/T13242-91, respectively. Mineralogy of quasi particle of sinter mixture and sinter of traditional and pre-briquetting sintering process, including morphology, microstructure and mineral compositions, was determined to demonstrate mechanism of pre-briquetting process on improving sintering process with high ratio of specularite.

\section{Results and Discussion}

\subsection{Effect of Pre-briquetting on Granulation}

Figure 4 shows the effect of pre-briquetting process on granulation compared with traditional process. Something of two aspects should be noticed: firstly, it indicates that the granulation efficiency of sinter mixture was exacerbated as the ratio of specularite increased under the condition of conventional granulation in traditional sintering process. As the ratio of specularite increased from $24 \%$ to $36 \%$, fraction of $+3 \mathrm{~mm}$ granule in sinter mixture after granulating was decreased from $56.96 \%$ to $51.52 \%$, permeability index was reduced from 0.214 J.P.U to 0.193 J.P.U. Secondly, the granulation efficiency of sinter mixture could be improved significantly by use of pre-briquetting process. As comparison of pre-briquetting process with traditional process showed in Fig. 4 and Table 5, as the ratio of specularite was $24 \%, 30 \%$ and $36 \%$ respectively, correspondingly, the ratio of $+3 \mathrm{~mm}$ in sinter mixture was $65.85 \%, 68.31 \%$ and $66.11 \%$, increased by $15.61 \%, 24.00 \%$ and $22.07 \%$ respectively. In the meantime, the permeability index was also heightened to 0.236 J.P.U, 0.243 J.P.U and 0.243 J.P.U, increased by $10.28 \%, 19.70 \%$ and $25.91 \%$ respectively. The test results proved that the pre-briquetting process has very obvious effect on strengthening granulation of sinter mixture for specularite, and the function gets more significant with the specularite ratio increased in blends.

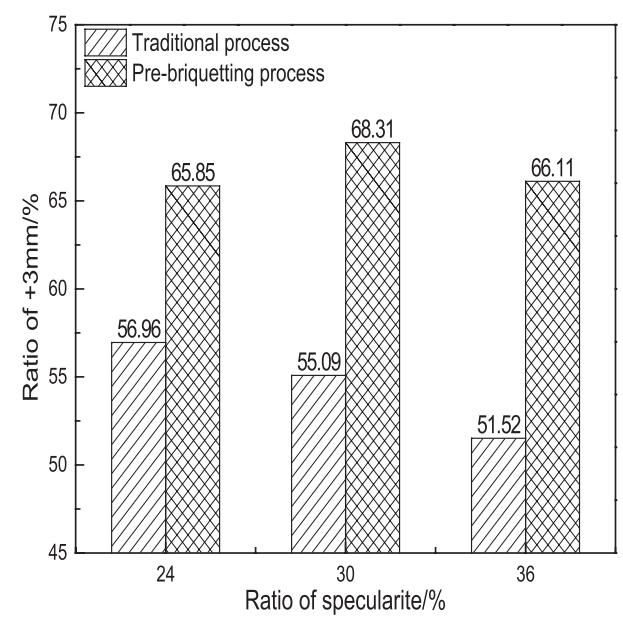

(a)
For size distribution of sintering layer, issues of two aspects need to be controlled in order to reduce the permeability resistance of sinter bed. The one is increasing the whole grain size, and the second is reducing the content of fine fraction in the mixture. ${ }^{22)}$ The difference of granules between these two processes can be observed in Fig. 5. In traditional process, there are small part of specularite particles adhered to the quasi particles like granule $+3 \mathrm{~mm}$ and most of specularite particles are scattered in granules -1 $\mathrm{mm}$. Meanwhile, there are more and coarse quasi particles in pre-briquetting process, some of which are particles that generated from pre-briquetting and granulated again by drum granulator. Besides, less of specularite particles are found in granules $-1 \mathrm{~mm}$, also the color of quasi particles presents earthy browns which is difference with its color in traditional process as shown.

Normally after granulation, the fine particles will be divided into two parts, either adhered on the surface of quasi particles or scattered in fine granules. However, the dense and smooth surface with hydrophobic, regular shape and undesirable size distribution of specularite particles lead to poor granulating performance, and then resulted in that the specularite particles were dispersed in the sintered mixture separately or filled in the gap between the quasi particles, with few can adhere on the surface of quasi particles. It is not surprising that increase of specularite ratio causes significant increase of the fine fraction content and decrease of permeability in the traditional sintering process. In addition, with the proportion of other iron ore fines declined due to the ratio of specularite concentrate increase, the nuclear particles of $+3 \mathrm{~mm}$ will be reduced, and further the number of quasi particles which act as the skeleton of sinter bed will be

Table 5. Comparison enhanced granulating results of prebriquetting with traditional process.

\begin{tabular}{cccc}
\hline Ratio of specularite & $24 \%$ & $30 \%$ & $36 \%$ \\
\hline $\begin{array}{c}\text { Increase ratio of }+3 \mathrm{~mm} \text { in } \\
\text { granules }\end{array}$ & $15.61 \%$ & $24.00 \%$ & $22.07 \%$ \\
\begin{tabular}{c} 
Increase of KD \\
\hline
\end{tabular} & 0.022 J.P.U & 0.040 J.P.U & 0.050 J.P.U \\
\hline
\end{tabular}

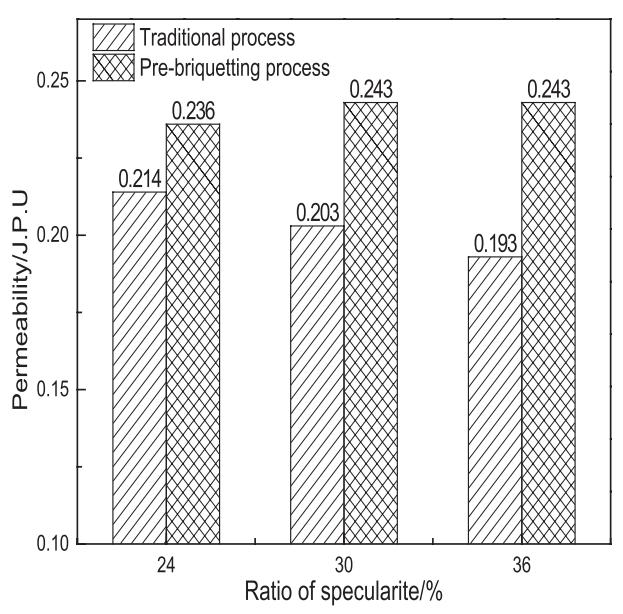

(b)

Fig. 4. Effect of pre-briquetting process on the ratio of $+3 \mathrm{~mm}$ in sinter mixture (a) and the permeability index (b) of sinter layer compared with traditional process. 


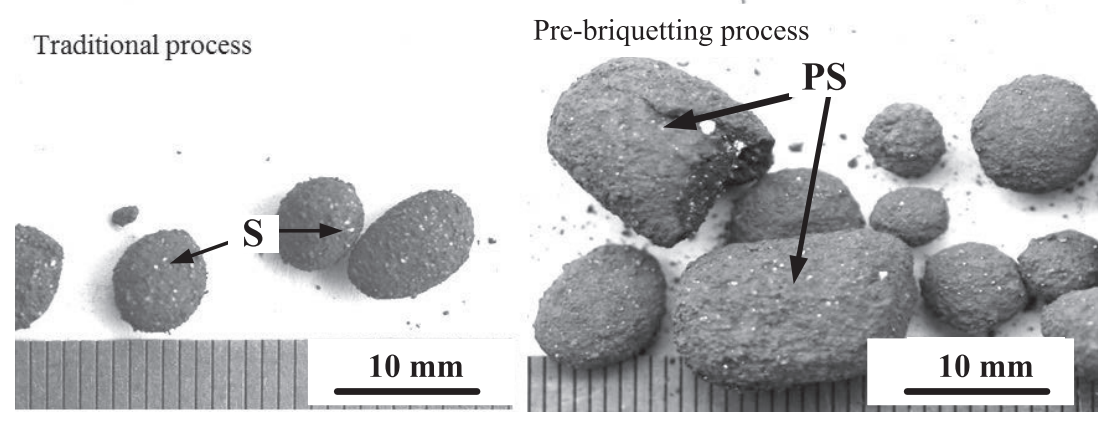

(a) Quasi particles $+3 \mathrm{~mm}$

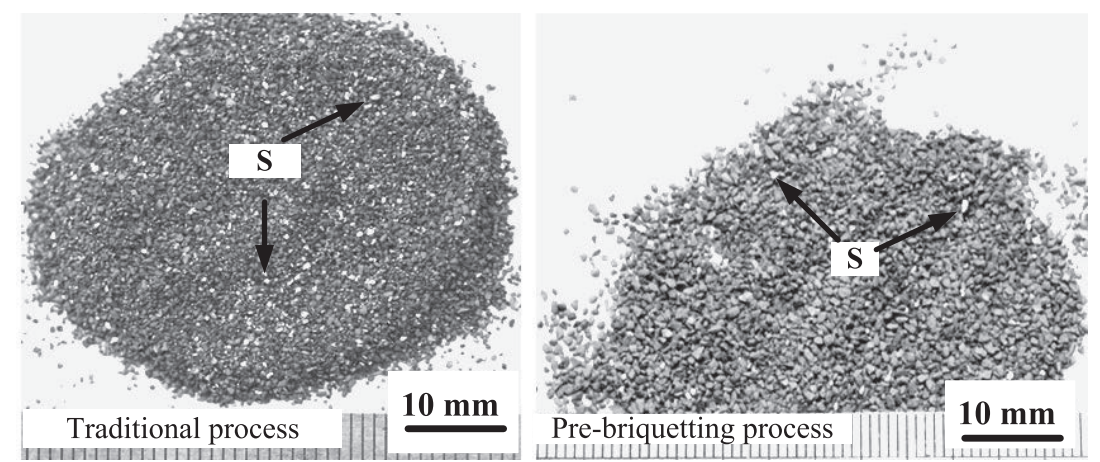

(b) Particles $-1 \mathrm{~mm}$ in granules

Fig. 5. Comparison of granules between pre-briquetting process and traditional process at ratio of $36 \%$ specularite, S-specularite particle, PS-particle of specularite made from pre-briquetting.
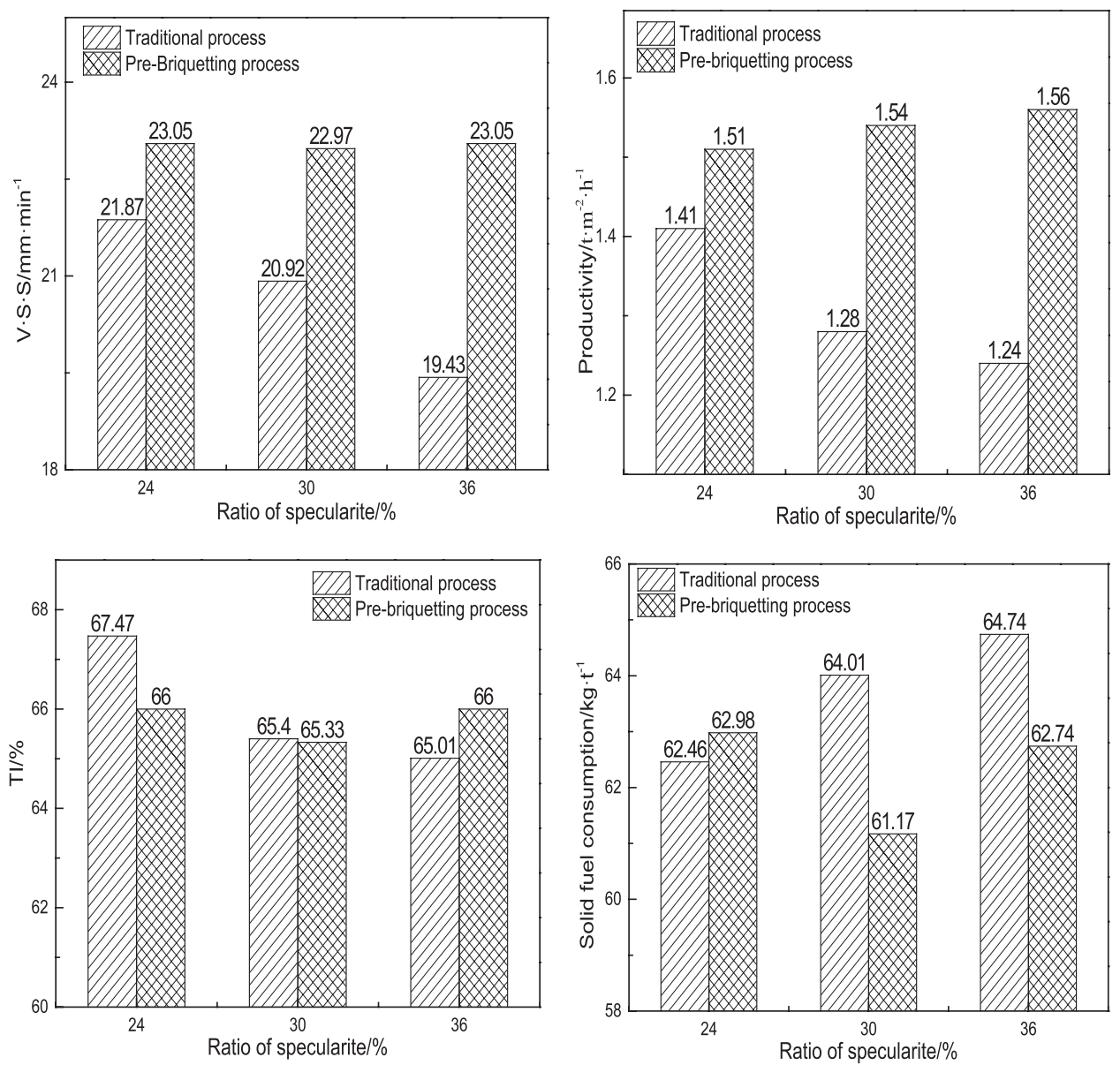

Fig. 6. Effect of pre-briquetting process on the sintering performance (the vertical sintering speed, productivity, tumble index of sinter and solid fuel consumption) compared with traditional process. 
also reduced, finally takes adverse effect on the permeability of sinter bed and results in the deterioration. However, the distribution of specularite particles has significant change after pre-briquetting process, most of specularite particles are molded alone under the force of double reversal rollers, a few part of dispersive particles adhered to the quasi particles, and the fraction of scattered in granules $-1 \mathrm{~mm}$ is significantly reduced compared with traditional process. Meanwhile, the quasi particle size is larger and generally over $10 \mathrm{~mm}$ or more, which can fully compensate for the shortage of sinter bed skeleton because of coarse fines ratio dropped with ratio of specularite raised in blends.

\subsection{Effect of Pre-briquetting on Sintering Performance}

Figure 6 compares sintering indices for the two different sintering processes. Results for pre-briquetting process tend to be better than those for the traditional process. As shown by Fig. 6, with the ratio of specularite increased from $24 \%$ to $36 \%$, the productivity and quality of sinter were in decline for traditional process, the productivity decreased from $1.41 \mathrm{t} / \mathrm{m}^{2} \cdot \mathrm{h}$ to $1.24 \mathrm{t} / \mathrm{m}^{2} \cdot \mathrm{h}$, TI declined from $67.47 \%$ to $65.40 \%$, and solid fuel consumption increased by $2.28 \mathrm{~kg} / \mathrm{t}$. However, the sintering performance could be improved after adopting the pre-briquetting process, and especially when the ratio of specularite reaches $36 \%$. The vertical sintering speed increased from $19.43 \mathrm{~mm} / \mathrm{min}$ to $23.05 \mathrm{~mm} / \mathrm{min}$, productivity increased from $1.24 \mathrm{t} / \mathrm{m}^{2} \cdot \mathrm{h}$ to $1.56 \mathrm{t} / \mathrm{m}^{2} \cdot \mathrm{h}$ which increased by $25.81 \%$, TI increased slightly from $65.01 \%$ to $66.00 \%$, moreover, the solid fuel consumption fell by 2.00 $\mathrm{kg} / \mathrm{t}$. Besides, on that condition that the return fines balanced $(\mathrm{RFB}=1 \pm 0.05)$, the yields in our sintering tests are $68 \%$ around and have nothing to do with the ratio of specularite and different sintering processes. Through comparing the effect of pre-briquetting process on sintering performance with traditional process, the results indicated that prebriquetting process acts a significant role on strengthening sintering performance and promoting the ratio of specularite in blends.

The change of macroscopic and microscopic structure of sinter can be observed in Figs. 7 and 8. According to this observation, briquettes of specularite kept their shapes after sintering and existed independently without assimilating or part assimilating into surrounding materials in the pre-briquetting process. Because of coating by the existing liquid phase or being independent as large briquettes of specularite in the sinter, less liquid phase was needed for bonding in the sinter, by which the shortcomings of low degree of assimilation and melt generation with refractory for specularite can be avoided.

Besides, there is obvious difference in the mineralogical aspects between the sinter contains $36 \%$ specularite of traditional and pre-briquetting process, as shown in Fig. 8. There are no uniform liquid phase distribution and poor $\mathrm{Fe}_{2} \mathrm{O}_{3}$ crystalline interconnections inside which existing some calcium silicate phase, and few calcium ferrite bonded phase which is only $23.50 \%$ (shown in Table 9). Therefore the product sinter in traditional process possessed loose microscopic structure with larger pore and more crack. Meanwhile, for the sinter of pre-briquetting process, there is better interconnection of $\mathrm{Fe}_{2} \mathrm{O}_{3}$ crystalline through silicate bonded phase inside the independent briquettes of specularite (Fig. 8 (b), left) and more calcium ferrite bonded phase with small pore structure in the other parts of sinter (Fig. 8(b), right). It is because of that sinter of pre-briquetting process was divided into two parts, the independent briquettes of specularite and the other parts rich in liquid bonding phase, whose basicity are 0.73 and 2.21 respectively while the basicity of sinter is still 1.85 as a whole. The fine specularite particles were readily assimilated to form coarse particles which were coated by sinter melt during sintering, meanwhile, the increase of basicity of materials except specularite promoted the liquid phase and calcium ferrite formation then enhanced the bonding strength of product sinter.

\subsection{Effect of Pre-briquetting on Metallurgy Perfor- mance of Sinter}

Metallurgy performance of sinter is expressed in Fig. 9. It can be seen that the reducibility (RI) and low temperature reduction disintegration $\left(\mathrm{RDI}_{+3.15}\right)$ have been improved slightly by adopting pre-briquetting process, and the higher the ratio of specularite, the more significant the improvement for $\mathrm{RI}$ and $\mathrm{RDI}_{+3.15}$. Compared with traditional process for Blend-2 which contains 36\% specularite, the RI and $\mathrm{RDI}_{+3.15}$ was increased by $1.63 \%$ and $1.99 \%$ respectively, which benefitted from the promotion of mineral composition and structure improved by pre-briquetting process. As Fig. 8 and Table 6 showed, loose microscopic structure with larger pore and more crack appeared in some parts of the

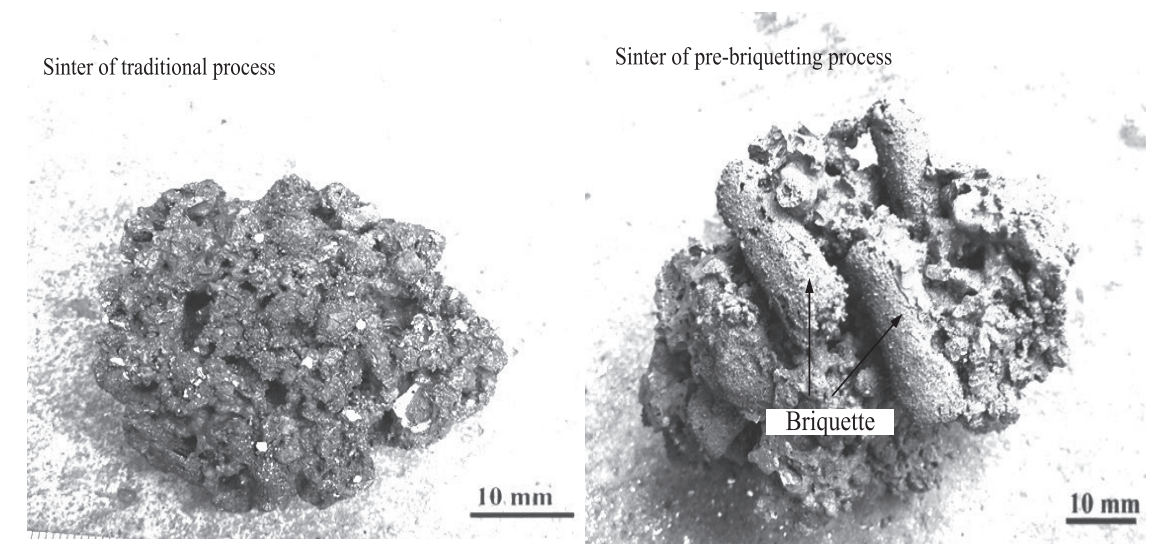

Fig. 7. Comparison of macroscopic structure of product sinter between pre-briquetting and traditional process at ratio of $36 \%$ specularite. 

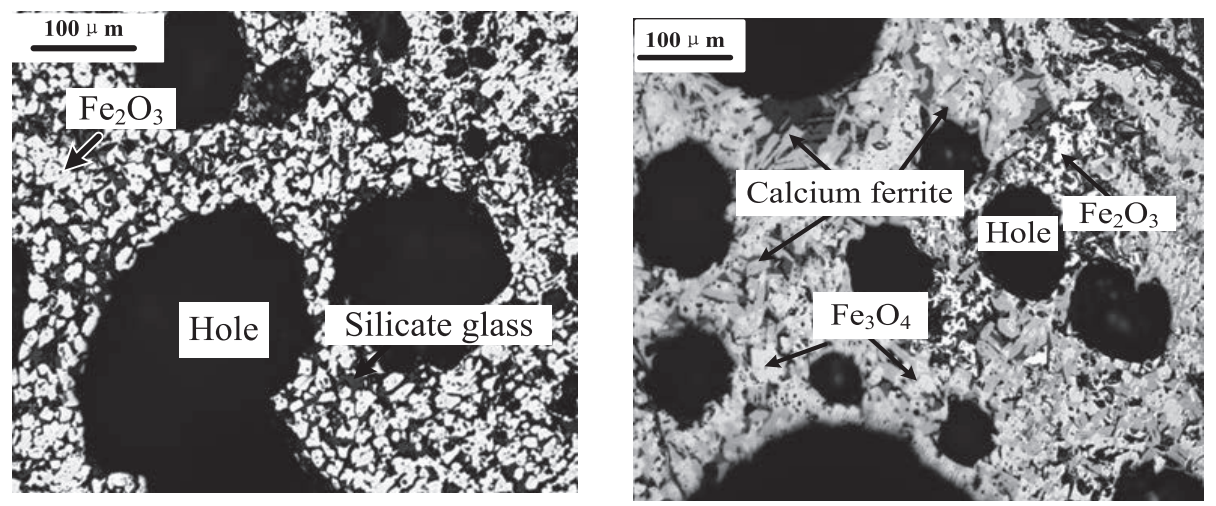

(a) Sinter of traditional process
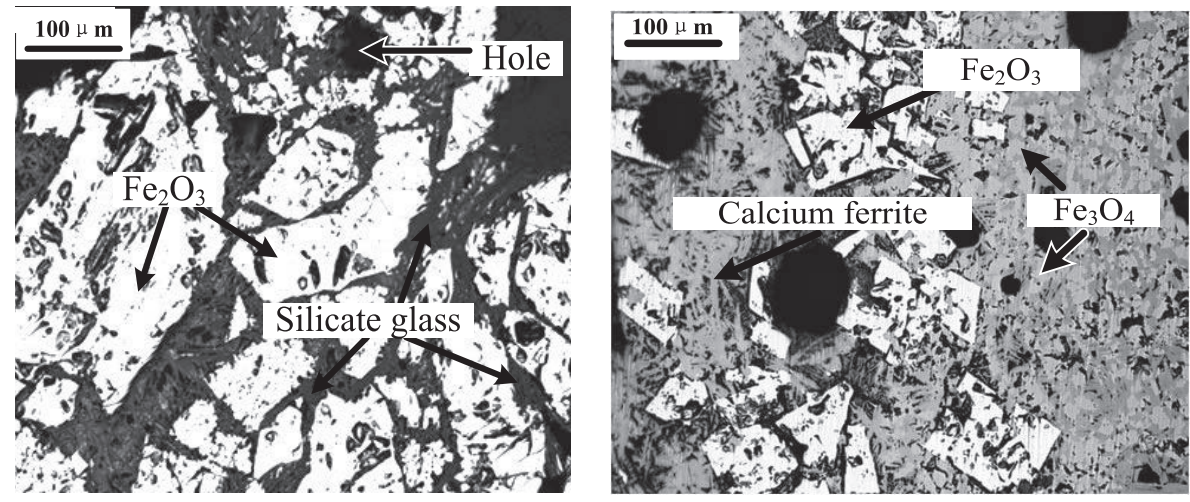

(b)Sinter of pre-briquetting process

Fig. 8. Comparison of microscopic structure of product sinter between pre-briquetting process and traditional process at ratio of $36 \%$ specularite.
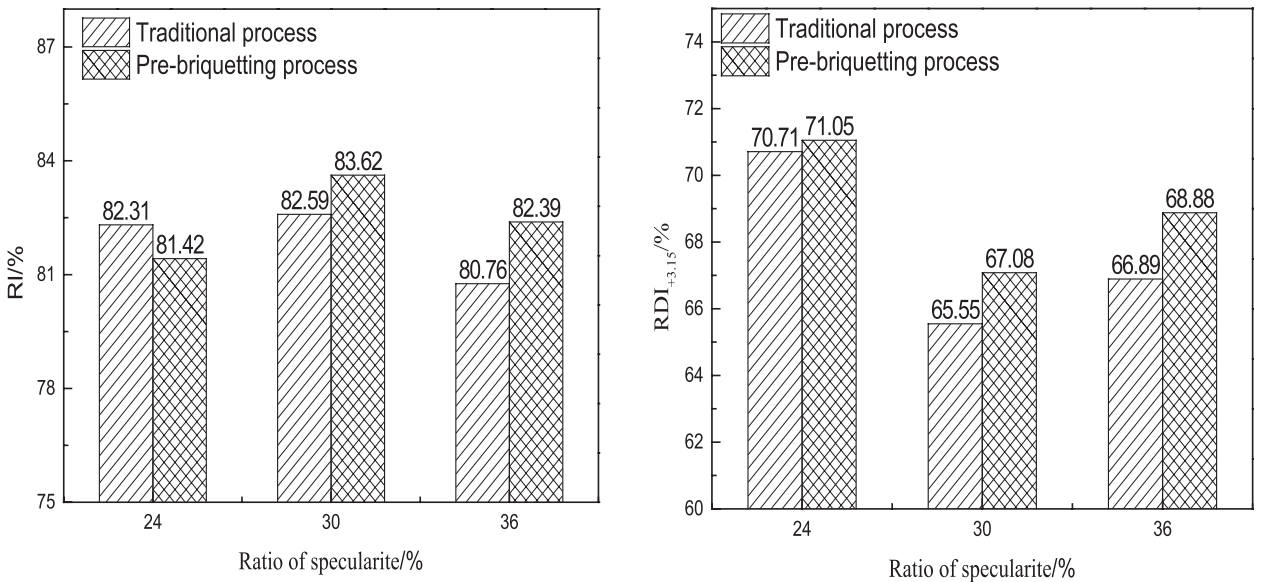

Fig. 9. Effect of pre-briquetting process on metallurgical performance comparison with traditional process.

Table 6. Mineral compositions of sinter*/area, \%.

\begin{tabular}{cccccccc}
\hline Process & Hematite & Magnetite & $\begin{array}{c}\text { Calcium } \\
\text { ferrite }\end{array}$ & fayalite & $\begin{array}{c}\text { Magnesium } \\
\text { ferrite }\end{array}$ & $\begin{array}{c}\text { Calcium } \\
\text { silicate }\end{array}$ & $\begin{array}{c}\text { Vitric \& } \\
\text { others }\end{array}$ \\
\hline TR Base & 35.76 & 19.48 & 22.62 & 6.62 & 5.73 & 3.98 & 4.81 \\
TR Blend-1 & 37.65 & 19.96 & 23.05 & 6.53 & 5.65 & 3.02 & 4.14 \\
TR Blend-2 & 38.82 & 19.52 & 23.50 & 6.72 & 5.74 & 2.56 & 3.14 \\
PR Base & 35.05 & 16.68 & 28.53 & 5.22 & 5.80 & 3.85 & 4.87 \\
PR Blend-1 & 34.51 & 18.02 & 28.63 & 5.06 & 5.76 & 3.53 & 4.29 \\
PR Blend-2 & 35.65 & 18.36 & 27.65 & 5.95 & 5.87 & 2.72 & 3.80 \\
\hline
\end{tabular}

*TR-traditional process, PR-pre-briquetting process 
sinter of traditional process and $\mathrm{Fe}_{2} \mathrm{O}_{3}$ distributed dispersive in the sinter, while the sinter of pre-briquetting process has more uniform structure no matter in independent specularite briquettes or other parts of sinter. Besides, the sinter of prebriquetting process has more calcium ferrite and less hematite, all of which would decrease reduction disintegration. Meanwhile, the increasing amount of calcium ferrite, higher and more uniform porosities improved the reducibility of pre-briquetting sinter.

\section{Conclusion}

(1) Pre-briquetting process can obviously promote the granulation of sinter mixture containing specularite by briquetting most of specularite particles to the nuclei of quasi particles in advance, especially in case of specularite occupy high ratio in mixture. The permeability index increases $25.91 \%$ compare with traditional process through pre-briquetting process under the condition that blended material contains $36 \%$ specularite, by reduce specularite particles that dispersed in the mixture and increase the course large particles act as skeleton,

(2) Pre-briquetting process increased the productivity by $25.81 \%$, increased TI of sinter slightly and reduced the solid fuel consumption by $2.00 \mathrm{~kg} / \mathrm{t}$ when the ratio of specularite reaches $36 \%$ in blended material. The new sintering process make the specularite form independent coarse particles coated by liquid phase and promote formation of calcium ferrite in bonding phase of sinter, ultimately avoid the shortcomings of specularite and obtain better sinter strength at a lower fuel rate.

(3) The pre-briquetting process is effective for improving the sintering performance of iron ore with poor granu- lation property because of different granulation model and better consolidation.

\section{REFERENCES}

1) L. Lu: Iron Ore 2015, Woodhead Publishing, London, (2015), 42.

2) Y. S. Jiao, S. C. Jiang and J. W. Wang: China Min. Mag., 22 (2013), 11.

3) P. X. Lei: China Min. Mag., 21 (2012), 1.

4) S.-P. Wang: Res. Iron Steel, 36 (2008), No. 6, 1

5) G. D. Wang: Sinter. Pelletizing, 27 (2002), 4.

6) Y. Z. Zhang, X. P. Feng, Z. G. Li, H. S. Yin and J. J. Tian: Multipurp. Utili. Miner. Resour., 01 (2004), 15.

7) T. Jiang, G. Q. He, X. Q. Li, Z. K. Tang and G. H. Li: Cent. South Univ. (Sci. Technol.), $\mathbf{4 0}$ (2009), 851.

8) D. Q. Zhu, Y. Y. Tang, V. Mendes, J. Pan and Y. Zhai: Univ. Sci. Technol. Beijing, 31 (2009), 30.

9) J. J. Fan, G. Z. Qiu, T. Jiang, Y. F. Guo, H. Z. Hao and Y. B. Zhang: J. Cent. South Univ., 19 (2012), 2611.

10) R. T. Johnson: U. S. Patent, No. 3, 370, 936, (1968).

11) B. Wang, H. M. Li, W. Yu and J. Pan: Sinter. Pelletizing, 33 (2008), 19

12) J. Pan, D. Q. Zhu, P. Hamilton, X. L. Zhou and L. Wang: ISIJ Int., 53 (2013), 2013.

13) J. Y. Hwang, J. Drelich, J. Downey, T. Jiang and M. Cooksey: 2nd Int. Symp. on High Temperature Metallurgical Processing, John Wiley \& Sons, New York, (2011), 197.

14) J. Y. Hwang, J. Drelich, J. Downey, T. Jiang and M. Cooksey: 2nd Int. Symp. on High Temperature Metallurgical Processing, John Wiley \& Sons, New York, (2011), 211.

15) D. Q. Zhu, Z. Y. Wang, J. Pan, L. I. Jian and X. U. Xiao-Feng: Cent. South Univ., 37 (2006), 878.

16) H. M. Li, D. Q. Zhu, J. Pan and F. Jiang: Min. Eng., 11 (2013), 41.

17) T. Jiang, G. H. Li, H. T. Wang, K. C. Zhang and Y. B. Zhang: Ironmaking Steelmaking, 37 (2009), 1.

18) W. Chen: Henan Metall., 20 (2012), 6.

19) C. Takano and K. Pohlmann: 6th Int. Cong. on the Science and Technology of Ironmaking, Associacao Brasileira de Metalurgia, Materiais e Mineracao, Rio de Janeiro, (2012), 1563.

20) S. Kawachi and S. Kasama: ISIJ Int., 51 (2011), 1057.

21) C. Takano and K. Pohlmann: 6th Int. Cong. on the Science and Technology of Ironmaking, Associacao Brasileira de Metalurgia, Materiais e Mineracao, Rio de Janeiro, (2012), 2541.

22) J. Y. Fu, T. Jiang and D. Q. Zhu: Sintering and Pelletizing, Central South University of Technology Press, Changsha, (1996), 102, 178. 